\title{
Nutritional Aspects in Heart Failure
}

\section{Pinho $\mathrm{CPS}^{* 1}$ and da Silveira $\mathrm{AC}^{2}$}

${ }^{1}$ Specialist in Clinical Nutrition by the Associação Brasileira de Nutrição (ASBRAN), Master's degree in Nutrition from the Universidade Federal de Pernambuco (UFPE)

${ }^{2}$ Specialist in Clinical Nutrition by the Hospital das Clínicas de Pernambuco (HC/UFPE), Attending Master's degree in Nutrition by the Universidade Federal de Pernambuco (UFPE)

*Corresponding author: Cláudia Porto Sabino Pinho, Specialist in Clinical Nutrition by the Associação Brasileira de Nutrição (ASBRAN), Master’s degree in Nutrition from the Universidade Federal de Pernambuco (UFPE), Recife-PE, Brazil, Postal Code: 52041-020, E-mail: claudiasabinopinho@hotmail.com Citation: Pinho CPS, da Silveira AC (2014) Nutritional Aspects in Heart Failure. J Nutr Health Sci 1(3): 305. doi: 10.15744/2393-9060.1.305

Received Date: June 09, 2014 Accepted Date: November 03, 2014 Published Date: November 06, 2014

Abstract
Heart failure (HF) is a complex clinical syndrome, of a progressive character, that has a limited prognostic factor and manifested by
various extracardiac aspects. It represents a serious and growing public health problem worldwide, both for its high prevalence and
the severity of its clinical manifestations, being the final common pathway of most diseases. Undernutrition is often associated with
HF, especially in the later stages of the disease, and may chronically reach cardiac cachexia, a severe manifestation related to poor
clinical prognosis. Nutritional care is accepted as an integral and indispensable part of the treatment of HF and seeks to improve the
nutritional status of the patient, aiming to replenish energy reserves, increasing skeletal muscle tissue and improving exercise capacity.
Micronutrient deficiency is common in patients with HF and its origin seems to be multifactorial, among which prolonged use of
diuretics, low dietary intake and increased nutrient losses are related. In this review the nutritional aspects will be addressed for HF,
with emphasis on the implications and nutritional recommendations.

\section{Introduction}

Heart failure (HF) can be defined as an abnormality of the cardiac structure or function that leads to decreased ventricular filling and ejection capacity leading to failure of the heart to provide oxygen at a rate consistent with the requirements of metabolizing tissues rate [1]. It is a complex clinical syndrome, of a progressive character, that has a limited prognostic factor and manifested by various extracardiac aspects, including neuroendocrine activation and cytokine release [2-5].

The HF is a multifactorial disorder that involves multiple organ systems in its pathogenesis and strongly affects the quality of life of affected patients [6], causing functional limitation and requiring immediate therapeutic intervention [5]. It represents a serious and growing public health problem worldwide, both for its high prevalence and the severity of its clinical manifestations, being the final common pathway of most diseases [7-9].

Clinical manifestations in patients with HF include fatigue, dyspnea during daily activities and paroxysmal nocturnal dyspnea, hepatomegaly, intolerance to physical exertion, night cough and water retention, which can cause pulmonary congestion and peripheral edema $[9,10]$. In recent decades, with a better understanding of the disease process, it became clear that the pathological changes involve not only the cardiovascular system but also the neuroendocrine, immune, musculoskeletal, hematologic, renal and gastrointestinal systems as well as the nutritional status [11].

Undernutrition is commonly found in patients with HF, mainly in the most advanced stages of the disease, being related with an enhanced risk of complications and mortality [12]. The implementation of effective nutritional strategies in HF remains a therapeutic challenge in clinical practice. In this review the nutritional aspects will be addressed for HF, with emphasis on the implications and nutritional recommendations.

\section{Undernutrition and HF}

Undernutrition is a classic manifestation and is often associated with HF. Within the list of common manifestations of the disease, varying degrees of protein-calorie depletion can be found, as well as extreme cases, generically called cardiac cachexia [13]. 
Undernutrition can occur due to inadequate intake, the altered metabolism, the pro- inflammatory state, increased oxidative stress and increased nutrient loss [6,7], resulting in lean body mass depletion (including vital organs such as the myocardium itself), with negative implications on functional capacity, and increased post-operative complications and mortality [11]. Studies with small samples demonstrate that lack of appetite may explain up to $50 \%$ of cases of undernutrition in patients with any chronic illness [14]. Anorexia in HF is a consequence of reduced intake of nutrients or combination of absorptive and metabolic changes (hypermetabolism, hypoxia, increased energy expenditure, inflammation) $[6,11,15]$. Moreover, changes in the digestive tract, such as gastric compression and hepatic congestion, cause postprandial feeling of fullness [16]. Unpalatable diets and exhaustion during feeding further contribute to inadequate nutrient intake [11].

The loss of nutrients is due to the bowel dysfunction in HF, explained by hypoperfusion and edema of the bowel. A study demonstrated an increase of the ileum wall and ascending, descending, transverse and sigmoid colon of patients with the disease compared to their controls [7,14,17]. The edema of the bowel loop would be responsible for malabsorption of lipids, protein loss and other symptoms such as nausea and anorexia $[6,15,17]$. Furthermore, the chronic use of diuretics may contribute to the increased losses of nutrients $[10,11]$.

HF patients had alterations in the anabolism/catabolism balance resulting from neurohormonal changes marked by increased levels of catabolic factors (norepinephrine, epinephrine, angiotensin II, cortisol, free radicals and inflammatory cytokines) and resistance to anabolic hormones such as the growth hormone (GH) and insulin. These changes contribute to an increased energy expenditure in resting $[6,18]$. Patients in functional class III and IV show an increased basal metabolic rate around $18 \%$, compared with healthy subjects [19]. The increased energy demands for the work of the respiratory muscles, the hypertrophied myocardium and the hematopoietic system contributes to this increase in the basal metabolic rate $[6,20]$.

Weight loss in patients with HF is marked by a disproportionate mobilization of muscle and fat tissue, protein degradation being a major change in disease progression $[21,22]$. The reduction of muscle mass is associated with intolerance to early exercise, fatigue, less strength, and hence deterioration in quality of life [23]. The presence of undernutrition is an important predictive factor for reduced survival of patients, regardless of important variables such as age, functional class and ejection fraction [6,24]. The incidence of undernutrition in HF is high and increases hospital mortality. Although related to complex mechanisms, undernutrition in patients with HF is a reversible condition with serious nutritional assessment and monitoring, early detection and proper diet [25].

\section{Cardiac cachexia}

Chronic diseases in general affect the nutritional status of the patient and undernutrition affects the course of chronic disease, and this relationship is assessed according to both factors. Nutritional deterioration imposed by HF is classically known as cardiac cachexia, whose presence has important prognostic implications [24,26,27].

Cardiac cachexia appears after years of progressive deterioration of the myocardial function [28]. The pathophysiological mechanisms involved in the etiology of cachexia associated with HF have not been fully elucidated. It is suggested that this is a multifactorial neuroendocrine and immunologic disease, wherein a complex balance between anabolic and catabolic processes can cause weight loss in patients with HF [29].

It is important to differentiate cachexia from undernutrition or anorexia, which are reversible conditions with adequate food intake, which hardly occurs in cachexia [30,31]. Undernutrition and anorexia are often considered as the main causes of cardiac cachexia. However, these conditions predominantly produce the loss of adipose tissue while cachectic patients experience loss of muscle mass, fat and bone mass, indicating generalized weight loss [3]. It was found that $68 \%$ of HF patients have severe muscle atrophy and when the disease is in an advanced phase a number of them develop osteoporosis [28].

The cardiac cachexia is characterized by the predominance of lean body mass loss, being caused by many factors, for instance the malabsorption of fat, the increase of the catabolic catecholamines (norepinephrine, epinephrine, cortisol) and stages of alpha tumor necrosis factor (TNF- $\alpha$ ), as well as the reduction in the production of many anabolic components [32]. A large number of mechanisms to compensate the defective myocardial function is activated to protect the heart and blood flow, leading to a complex and chronic inflammatory state. The mediators involved in this process include proinflamatory cytokines, catecholamines, cortisol proteins and natriuretic peptides [3,33]. The TNF- $\alpha$ activation induces the apoptosis through specific receptors in the cells surface and activates protein degradation [34]. The TNF- $\alpha$ is partially responsible for decrease in blood flow to skeleton muscle tissue, aggravating the endothelial dysfunction [35]. The proinflamatory cytokine Interleukin-6 (IL-6) engenders the acute phase response [36], which maintenance requires an excess of essential amino acids provided at the expense of organism protein loss [37].

Experimentally, it was found that the development of cachexia may lead to additional cardiac changes and exacerbation of a preexisting framework of HF $[3,38,39]$. Moreover, the reduction of intestinal absorption is more evident in patients with cachexia, especially fat absorption, and it is suggested that these changes are involved in its etiology [40]. 
As a result of cachexia changes occur in practically all organs and systems. Among the repercussions are cardiac abnormalities, abnormalities of the respiratory function, marked decrease in muscle and bone mass, reduced ability to concentrate and urinary acidification, decreased wound healing, susceptibility to pressure ulcers in bedridden patients, changes in the gastrointestinal tract, with reduced immunity and increased risk of infections [11].

It can often be difficult to diagnose cachexia in patients with HF, as the presence of an edema affects the assessment of body weight and other anthropometric measurements. Furthermore, the interpretation of laboratory nutritional assessment is also limited due to the effects of excessive extracellular fluid [41].

In the absence of a consensual, universally accepted definition, some definitions are proposed for its diagnosis. Anker et al [24] suggested a definition based on the applicability of simple, non-edematous, unintentional weight loss in the absence of other consumptive diseases, $7.5 \%$ above the normal weight for longer than 6 months. Marked weight loss in a shorter period could be related to the exacerbation of the disease itself and not to immune and neuroendocrine changes that characterize cachexia.

Subsequently, it was shown that reduction of $6 \%$ of the weight is related to poor prognosis, with this criterion adopted for diagnosis [42]. At the Consensus Conference on Cachexia, in 2006, a group of experts proposed a definition based on the loss of greater than $5 \%$ in less than 12 months during a chronic illness, or BMI $<20 \mathrm{~kg} / \mathrm{m}^{2}$, associated at least with three of the following criteria: 1) decrease in muscle strength, 2) fatigue, 3) anorexia, 4) reduced rate of fat-free mass and 5) biochemical abnormalities, such as inflammation, anemia or reduced serum albumin concentration [30,31]. The prevalence of cachexia may vary depending on the diagnostic criteria used and the functional class of HF. Studies have indicated percentages ranging from 16\% to 34\% [24,42].

Cardiac cachexia can lead to a devastating prognosis. After analysis of a survival curve 18 patients with HF in outpatient treatment, an estimated mortality rate of $50 \%$ in cachectic individuals and $17 \%$ for those without this condition was calculated [14,24].

\section{Obesity}

The increase in BMI raises the risk of developing HF in both sexes and regardless of other risk factors [43,44]. This increased risk conferred by obesity is attributed to hemodynamic adaptations to withstand intense adipose tissue metabolism and oxygen consumption is increased [45]. Cardiac output rises at the expense of an increase in circulating blood volume, leading to a chronically high state of preload, which favors the increase in ventricular dimensions [46].

Furthermore, there are evidences that a bigger fatty acids accumulation, as long as its heart muscle cells oxidation decrease, process known as lipotoxicity, can occur more frequently in obese individuals. Lipotoxicity can lead to heart cells apoptosis, besides functional change of the organ by affecting its contractility [47]. The fatty acids increase also contributes to the appearance of insulin resistance [48], that as well as obesity, was identified as a predictor of heart failure [49].

The Framingham study that evaluated 5,881 patients showed a positive relationship between BMI and the incidence of HF, indicating the increased risk of developing the disease in 5\% to $7 \%$ for men and women for every one-unit increase in the value of normal BMI. Another study found that obese individuals had a double risk of cardiac decompensation as compared to eutrophic ones [43]. Estimates indicate that 15 to $35 \%$ of HF patients are obese and 30-60\% are overweight [50].

However, although it is considered a risk factor and precipitant of HF, paradoxically, obesity has been identified as a predictor of longer survival in patients with the disease, when compared to well-nourished or malnourished individuals [51-53]. This "obesity paradox" or "reverse epidemiology" has been reported in other chronic conditions (nephropathy on dialysis, advanced age, chronic obstructive pulmonary disease, liver cirrhosis, advanced cancer and acquired immunodeficiency syndrome [54,55] and in several studies that evaluated patients with HF, but this remains controversial [51,55-58].

Patients who are overweight have fewer complications during hospitalizations, lower risk of sudden death and better short- and long-term prognosis than normal and underweight individuals [59]. Oreopoulos et al. [60], in a meta-analysis to assess the relationship between increasing BMI and mortality in patients with HF, reported that in nine observational studies with 28.209 individuals overweight and obesity were associated with lower mortality.

This protective effect conferred by obesity in HF is related to a greater energy reserve for patients who are vulnerably exposed to catabolic changes and hormonal activation of stress systems. Therefore, being overweight or obese in HF may reflect the metabolic reserves have not been used, providing more and better tolerance to metabolic stress caused by the disease [55,61]. Furthermore, the adipose tissue produces receptors for tumor necrosis factor (TNF- $\alpha$ ), resulting in an increase of these receptors in obese individuals. This increase may have a cardioprotective role, neutralizing and / or reducing the catabolic effects of TNF- $\alpha$ [61].

Therefore, to control excess weight is beneficial to prevent the HF, but once this is installed, avoiding weight loss reduces mortality [62]. There is evidence that weight loss in patients with HF is associated with disproportionate mobilization of muscle and adipose tissue, with increased protein degradation $[13,22]$. There are still doubts about the benefit of maintaining a BMI above normal limits, with no formal recommendations regarding the indication of weight loss or maintenance of high BMI for individuals with HF overweight. 


\section{Nutritional Assessment}

Considering that the nutritional status represents a risk element for the HF occurrence while being a condition associated with the disease development and progression, the nutritional assessment of those patients must be object of monitoring in order to prevent the linked risks.

Despite the historical and secular entanglement between HF and undernutrition, is not yet defined what would be the best parameter to express the nutritional status of patients with the disease. Nutritional diagnosis in these patients is particularly hampered by the presence of water retention, which can mask the evaluation result. Anyway, the nutritional status of patients with HF should be systematically assessed in the context of multidisciplinary care, the benefits of which are well established [10].

The BMI, a parameter routinely used to diagnose the nutritional status, has reduced sensitivity to certify the condition of severe undernutrition among patients with HF [63]. The Mini Nutritional Assessment (MNA) has been identified as a useful tool for identifying patients with HF at high nutritional risk [26].

The triceps skinfold (TSF) also appears to be adequate to express the adipose reserve method in these patients. A study that evaluated the prognostic value of various anthropometric parameters (body mass index, subjective global assessment, TSF, waist circumference and arm circumference) revealed that the TSF was the only parameter able to differentiate between survivors and non-survivors and a prospective cohort of patients with HF [64]. The subjective global assessment is otherwise described as reliable and more sensitive in patients with HF [65].

The bioelectrical impedance analysis (BIA) has appeared in some articles as a way to assess body mass in patients with HF, but we question its validity in congested patients, whereas the extracellular fluid retention may overestimate fat-free mass [66]. The hydration status of these patients is variable and there may be a subclinical edema to compromise the body composition analysis. However, the BIA could be useful for determining the phase angle (AF) obtained from measurements of resistance (R) and reactance $(\mathrm{Xc})$ that are independent of the hydration status of the patient. Although their biological significance is not fully understood, the AF reflects the body cell mass, and for this reason it has been used as a nutritional indicator in adults and children [67-69]. Furthermore, it is one of the best indicators of cell membrane function and lower values are associated with higher morbibortality $[68,69]$.

Thus, there are no well-defined criteria to determine the nutritional status in patients with HF, as there is a certain scale to grade the different levels of organic impairment [13]. The literature indicates that no single method can accurately express the nutritional status of patients with the disease, and the information obtained from multiple parameters is more integrative and complementary $[70,71]$.

\section{Nutritional Recommendations}

Nutritional care is currently accepted as an integral and indispensable part of the treatment of HF and seeks to improve the nutritional status of the patient, aiming to replenish energy reserves, increasing skeletal muscle tissue and improving exercise capacity [29,72]. Considering that the disease may be associated with nutritional deficits, prevention and early intervention can improve the patient's condition and prognosis of the disease $[2,3,6,11]$. However, these therapeutic measures need to be individualized.

The HF is a syndrome with a high prevalence of multiple chronic comorbidities, but most guidelines are developed for patients with a single disease. However, the coexistence of other diseases, such as arthritis, kidney failure, diabetes mellitus or chronic lung disease, with the HF syndrome should require treatment modifications [73]. Moreover, one should consider the use of medications such as diuretics and anticoagulants that interfere with the nutritional status of some nutrients. The use of loop diuretics may lead to potassium, sodium and magnesium depletion in addition to hyperglycemia, hyperlipidemia and hyperuricemia [11,72]. The anticoagulants, on the other hand, can cause both mucosal injury in several parts of the gastrointestinal tract and facilitate blood loss through the digestive tract [74].

In addition to loss of nutrients, it has been found in some studies that patients with HF have inadequate intake of energy and nutrients [75,76]. Therefore, the guidance and dietary prescription should be preceded by nutritional diagnosis [65] by the available methods, including food history, and should not be restricted only to hydro - salt restriction [6].

If necessary, fluid restriction should be around 1000-1500 ml, and should always be made with patients with hyponatremia or symptomatic ones, and for the latter, the monitoring of body weight should be done on a daily basis [5,11]. It is important to note the appearance of fluid retention, which may be indicated by the sudden increase of two or more kilos in three days [72].

\section{Calories and Macronutrients}

For the calculation of energy needs, the practical method is recommended (calorie/kg dry weight/day), considering the nutritional status of the patient, and should be used around $25-30 \mathrm{kcal} / \mathrm{kg} /$ day) $[6,14,77]$. Previous studies indicate $28 \mathrm{kcal} / \mathrm{kg}$ weight for patients with adequate nutritional status and $32 \mathrm{kcal} / \mathrm{kg}$ weight for nutritionally depleted patients [22,72]. Energy requirements may also vary according to the functional class of HF. Patients in functional class III and IV show increased basal metabolic rate around $18 \%$, compared with healthy subjects $[19,72]$. 
The distribution of macronutrients in the diet does not differ much from the general population (Table 1). However, in relation to protein intake, patients with HF have higher requirements than the general population, ranging from $1.1 \mathrm{~g} / \mathrm{kg} \mathrm{dry}$ weight/day for patients with normal to $1.5-2.0 \mathrm{~g} / \mathrm{kg}$ dry/day for malnourished patients with cardiac cachexia or showing losses because of nephropathy and / or intestinal malabsorption $[10,11,14,22]$.

For patients with cardiac cachexia an energy intake of 40 to 50 calories $/ \mathrm{m}^{2}$ body/surface time (about 30 to $40 \mathrm{calories} / \mathrm{kg} / \mathrm{day}$ ) has been proposed, including $1.5-2 \mathrm{~g}$ protein/ $\mathrm{kg} /$ day [3,29].

It is important to be cautious with hypo- or hyperalimentation. Excessive intake of energy is related to increased physiological stress and with elevated plasma concentrations of catecholamines and insulin, resulting in increased reabsorption of sodium and water, and liver dysfunction, worsening HF $[11,29,78]$. The energetic substrates excess obtained by hypercaloric or unbalanced diets can contribute in certain occasions to the HF development and progression, through mechanisms related to glucotoxicity and lipotoxicity [79].

\begin{tabular}{|c|c|c|}
\hline $\begin{array}{c}\text { Energy and macronutrient } \\
\text { distribution }\end{array}$ & Recommendation & Authors \\
\hline Energy & 28 to $32 \mathrm{kcal} / \mathrm{kg}$ weight & Bocchi, 2009 [72]; Aquilani et al., 2003 [22] \\
\hline Carbohydrates & 50 to $55 \%$ of VCT & $\begin{array}{c}\text { Bocchi, 2009 [72]; Berry e Clarck, 2000 [2]; } \\
\text { Heart Failure Society of America, 2006 [80] }\end{array}$ \\
\hline Lipids & 30 to $35 \%$ of VCT & Bocchi, 2009 [72]; Heymsfield et al., 1981 [81] \\
\hline Proteins & $\begin{array}{c}15 \text { to } 20 \% \text { of VCT } \\
(1,1 \mathrm{~g} \text { to } 2,0 \mathrm{~g} / \mathrm{kg} / \text { day })\end{array}$ & $\begin{array}{c}\text { Bocchi, 2009 [72]; Quinn et al.\& Askanazi, 1987 [82] } \\
\text { Hernandez 2012 [14]; Aquilani et al., 2003 [22] }\end{array}$ \\
\hline Relation cal/g of $\mathrm{N}^{* *}$ & 120 a 160: 1 & Quinn \& Askanazi, 1987 [82] \\
\hline
\end{tabular}

* VCT $=$ total caloric value ; ${ }^{* *}$ calorie/gram of nitrogen

Table 1: Distribution of energy and macronutrients in the diet for individuals with HF

We recommend limiting the intake of saturated fats, trans fats, dietary cholesterol $(<200 \mathrm{mg}$ daily) and simple sugars [14,72]. Furthermore, it should be oriented the increased intake of mono- and poly-unsaturated fats, proteins of high biological value and complex carbohydrates with low glycemic response [14,72]. Hyperglycemia leads to changes in the redox system, increases oxidative stress and decreases the availability of nitric oxide, resulting in endothelial dysfunction; these effects are magnified in individuals with HF [83].

\section{Omega 3}

Supplementation with omega 3 comes as an adjunctive therapy for HF and is recommended by guidelines for the treatment of the disease $[1,72,73]$. Studies suggest that supplementation of polyunsaturated omega-3 fatty acids may improve ventricular systolic function, increase functional capacity, decrease the number of hospitalizations, reduce inflammatory markers and the incidence and mortality of $\operatorname{HF}[79,84,85]$.

In a prospective cohort study with a follow-up of 12.7 years, 52,972 Japanese people of both sexes aged 40-79, there was a lower mortality rate from all cardiovascular causes among individuals with higher consumption of foods rich in omega 3 , even lower for patients with only HF [85]. In the GISSI - HF study [86], which included 6,975 patients, 1 g of omega 3 added to optimized therapy resulted in a $9 \%$ reduction in mortality. An intake of omega-3-rich foods at least twice a week such as fish would be recommended $[14,77]$.

\section{Micronutrients}

The deficiency of micronutrients, such as selenium, thiamine, calcium, magnesium, zinc and vitamin D [6,14,72,87-89], is common in patients with HF and its causes seems to be multifactorial, among which prolonged use of diuretics, low dietary intake and increased nutrient losses are related [14,72,73]. Among the benefits observed in studies evaluating the impact of the supplementation of micronutrients' complexes in these patients, there is a greater exercise tolerance and reduced symptoms [14].

Witte et al [90], in a controlled double blind clinical trial to assess the impact of vitamin and mineral supplements in patients with $\mathrm{HF}$ with a percentage of ejection fraction of the left ventricle (\%LVEF) $\leq 35 \%$, found that when receiving a capsule with high doses of calcium, magnesium, copper, selenium, riboflavin, folate, vitamins A, B6, B12, C, D and E, and coenzyme Q10, patients showed a decrease in ventricular chambers, improved by $5.3 \pm 1.4 \%$ in $\%$ LVEF and quality of life scores compared to the control group that received placebo $(\mathrm{p}<0.05)$.

Therefore, supplementation of some micronutrients would be prudent, particularly for patients with chronic use of diuretics, who become deficient in water-soluble vitamins, especially thiamine, and some minerals, including potassium and magnesium, calcium, zinc e selenium $[11,15,18]$. Although the results of several studies suggest that supplementation of some micronutrients is likely $[87,90]$, there is no consensus on specific recommendations on nutritional HF, revealing the need for more experimental studies in this area. 


\section{Sodium}

Restricting sodium is commonly recommended for patients with HF by numerous authors and guidelines [5,91,92]. However, controversial results on sodium restriction do not allow a further definition of the optimal amount of this nutrient in the diet of patients with the disease. It seems consistent to consider its reduction only for patients in stages III and IV for symptom improvement $[5,11,72,73]$.

Diets containing $2 \mathrm{~g}$ of sodium were associated with reduced intake of calories and nutrients. Restriction of salt intake to $3 \mathrm{~g}$ only benefited patients with advanced HF [93]. The use of salts of potassium chloride may be considered, with monitoring of serum potassium in patients with renal disease and concomitant use of potassium-sparing diuretics [72].

\section{Thiamine}

Studies in Brazil showed that thiamine deficiency is observed in 30-33\% of patients with heart disease [76,88]. In patients with HF, it occurs mainly in people who are malnourished, elderly, and with a severe disease $[15,94,95]$. Vitamin B1 is a catalyst in many chemical processes involving the heart, the nervous system and the muscles. Its deficiency is well documented in patients with HF due to prolonged use of diuretics $[75,76,96]$. It is responsible for beriberi and high-output HF, reversible by restoration of serum levels of the vitamin [97].

For decades it has been shown that chronic use of high doses of loop diuretics in patients with HF is associated with the depletion of the thiamine reserves [15,98]. In one of these studies [88] a positive effect of spironolactone as sparing the spoliation of thiamine induced by furosemide was observed. Another study [89] found that thiamine replacement caused an average $13 \%$ increase in left ventricular ejection fraction, corroborated by other authors. Cunha et al [88] found in their study that thiamine deficiency was not associated with protein-energy undernutrition, suggesting that we should consider the possibility of vitamin deficiency even in eutrophic individuals.

Thiamine plays an important role in myocyte contraction, as demonstrated in experimental animal models [88]. It acts as a coenzyme in energy metabolism $[88,94]$, and its deficiency interferes with oxidative metabolism, favoring an accumulation of pyruvate and lactate, which can aggravate HF $[87,99]$. Therefore, although the doses for thiamine supplementation in patients with $\mathrm{HF}$ are not established [88], and there are no validated questionnaires for assessment of intake of this vitamin [95], supplementation in these patients can be justified by the benefits mentioned above and must be considered, especially in those with alcoholic etiology of IC. Being possible to suggest that values between the Recommended Dietary Allowance (RDA) and the Tolerable Upper Intake Level (UL) be considered to the patients in long-term use of high diuretics doses.

\section{Vitamin D}

Studies suggest that cardiovascular diseases are associated with hypovitaminosis D [100-102], especially those with HF, considering its limited activity, tendency to remain in the home environment, plus the lowest absorbency that commonly accompanies the disease [75]. A deficiency of this vitamin can lead to hypertension and increased cardiomyopathy [100]. An experimental study showed deterioration of myocardial contraction when patients are offered a diet low in vitamin D. Furthermore, it was found that these animals returned to a normal function when there was a supplementation of this vitamin [15].

In India, the deficiency of this vitamin was very prevalent, with reported rates of between 70 and 100\% [103-106]. It is commonly accepted that the pro-inflammatory immune response as well as vitamin D deficiency precede the development of HF [107]. Maintenance of normal serum vitamin D is important for the prevention and treatment of HF, justifying the need for supplementation on the occurrence or risk of this $[108,109]$. Nevertheless, controlled studies are necessary to establish the ideal dosage which benefits the HF patient.

\section{Iron}

In a meta-analysis that included 153,000 patients with HF there was a 37.2\% prevalence of anemia [110]. Several factors are related to the etiology in this group of patients, such as low food intake, decreased intestinal absorption, blood loss from the gastrointestinal tract, abnormalities in the production of red blood cells, worsening renal function, chronic inflammation, hemodilution and use of medications [75].

Anemia reduces the oxygen supply to the tissues, causing decreased renal perfusion and marked neurohormonal stimulation, and exacerbates the signs and symptoms of HF, such as loss of appetite, fatigue, edema and ischemia $[9,111]$.

There is a pathophysiological interrelationship between anemia, renal dysfunction and HF, featuring the cardio-renal-anemia syndrome, in which the three components form a vicious cycle in which each one is capable of causing or overstimulating the other $[112,115]$. The correction of anemia in HF translates into an improvement of the cardiac function (increased cardiac output, decreased left ventricular mass, prevention of left ventricular dilatation, improvement of NYHA functional class and myocardial ischemia) and renal function [115-117]. 
Although controversial, the specific treatment of anemia involves the correction of nutritional deficiencies and the use of erythropoiesis stimulating agents [75]. The replacement of intravenous iron may improve symptoms. The recommended dose is one ampoule of iron per week for ten weeks, or two ampoules every other week for five weeks, by monitoring monthly rates of hemoglobin/hematocrit and quarterly ferritin levels. The practical formula to calculate the total iron dose (in $\mathrm{mL}$ ) is: $\mathrm{N}$ ( $\mathrm{ml}$ ) $=[($ weight in $\mathrm{kg} \times 2.4 \times \mathrm{Dhb})+500 \mathrm{mg}] / 20$, where $\mathrm{N}=$ amount of iron in $\mathrm{mL}$ to be administered intravenously; Dhb=difference between the desired and found hemoglobin; $500 \mathrm{mg}=$ required reserve of iron $[9,117]$.

\section{Antioxidants}

Patients with HF have elevated oxidative stress resulting from increased production of free radicals or depletion of endogenous antioxidants $[87,118]$. Use of antioxidants as an adjuvant therapy for patients with HF is tentatively discussed in guidelines for treatment $[72,73]$.

HF patients have lower plasma selenium levels than healthy individuals. Selenium is an essential mineral for the synthesis of glutathione peroxidase and its deficiency has been identified as a cause of non-ischemic HF [87]. As zinc, manganese, copper, and some vitamins such as $\mathrm{C}$ and $\mathrm{E}$ and riboflavin, selenium is an antioxidant that can contribute to the reduction of oxidative stress and damage caused by it, while minimizing the deleterious effects of hypoxia [75,87].

Magnesium levels may also be decreased in patients with HF in $30 \%$ of cases [83], accompanied by muscle deficiency of this mineral, which may contribute to the symptoms of fatigue [15]. Hypomagnesemia can cause cardiac arrhythmias and decreased glucose tolerance in patients with HF [119]. Also, it is associated with poor prognosis and can cause positive balance of sodium and potassium [83].

HF has also been linked to zinc deficiency by urinary loss, gastrointestinal edema or low protein intake [75]. This micronutrient is part of the copper-zinc superoxide dismutase complex, capable of purifying the cell from free radicals [83]. Its deficiency can lead to decreased perception of taste, loss of appetite, immune abnormalities, delayed wound healing and increased susceptibility to developing pressure sores [75].

Vitamins C and A can also mitigate the damage by hypoxia and endothelial apoptosis in patients with HF [14,29,83].

\section{Nutritional therapy in $\mathrm{HF}$}

The indication for enteral nutrition for patients with HF is not specific, and should be considered, as with other pathological conditions, when oral feeding is impossible or when the individual cannot eat enough to meet $65 \%$ of their nutritional needs $[29,78]$. It has to be recommended as a strategy for prevention or treatment of cardiac cachexia $[6,23]$.

The use of feeding tubes should start with small volumes, gradually progressing and avoiding fluid overload [11,28]. Na terapia nutricional do paciente com IC é importante evitar a sobrecarga hídrica [11,28]. Formulas with a higher caloric density $(1,5$ a 2 $\mathrm{cal} / \mathrm{ml}$ ) should be used by enteral route in order to match the necessities in a lower volume. Fluid balance should be monitored and, in general, fluid restriction is indicated (1-1.5 liters/day)[28]. Seen in these terms, the formulas should also contain a high concentration of proteins per liter. In patients that need a less than 1 liter per day water restriction, special attention must be given to the micronutrients necessity. In case they do not meet the RDA, they should be supplemented.

Parenteral nutrition should be instituted when the gastrointestinal tract is not functioning or to supplement enteral nutritional support [29]. One should be careful with hyperalimentation, which can lead to cardiac decompensation [11,29,78]. Since patients with heart failure have low tolerance to the administration of large volumes, parenteral nutrition through a central venous access is used more often than peripheral access. It allows infusion of concentrated hyperosmolar solutions in lower volumes [11].

In this context, we highlight the need for a multiprofessional and interdisciplinary team in purpose of obtaining effective results.

\section{Conclusion}

Undernutrition is often associated with HF, especially in the later stages of the disease, and may chronically reach cardiac cachexia, a severe manifestation related to a worse clinical prognosis. The HF progression and its drug therapy at the diagnosis, even for eutrophic patients, leave them at potential risk of nutritional impairment and micronutrients deficiency, highlighting the need for systematically assessment of the nutritional status of those individuals in order to establish individualized and appropriate nutritional guidance.

For the nutritional recommendation of proteins, carbohydrates and lipids there are already specific guidelines, but not for vitamins and minerals. Studies step toward the need for micronutrients supplementation above the RDA to ensure the micronutrients support and address the enhanced losses, however it has only being established the quantities for iron supplementation.

Notwithstanding that is well pointed out by the literature the relevance of the HF nutritional monitoring, many studies will still be needed to formulate specific micronutrients dosage guidelines in the HF nutritional therapy. 


\section{References}

1. Perk J, Backer GD, Gohlke H, Graham I, Reiner Z, et al. (2012) European Guidelines on cardiovascular disease prevention in clinical practice (version 2012). Eur Heart J 33: 1635-701.

2. Berry C, Clark AL (2000) Catabolism in chronic heart failure. Eur Heart J 21: 521-32.

3. Anker SD, Sharma R (2002) The syndrome of cardiac cachexia. Int J Cardiol 85: 51-66.

4. Sharon Ann Hunt, William T. Abraham, Marshall H. Chin, Arthur M. Feldman, Gary S. Francis, et al. (2005) Guideline update for the diagnosis and management of chronic heart failure in the adult. J Am Coll Cardiol 46: 1116-43.

5. Bocchi EA, Vilas-Boas F, Perrone S, Caamaño AG, Clausell N, et al. (2008) I Latin American Guideline to assessment and treatmentin decompensatedheart failure. Arq Bras Cardiol 85: 1-48.

6. Sahade V, Montera VSP (2009) Nutritional treatment for heart failure patients. Rev Nutr 22: 399-408.

7. Romeiro FG, Okoshi K, Zornoff LAM, Okoshi MP (2012) Gastrointestinal Changes associated to Heart Failure. Arq Bras Cardiol 98: 273-7.

8. Cabrera AJR, Zerquera JMC, Ortiz ABH (2007) Progresosenlainsuficiencia cardíaca. MedIntMex 23: 321-9.

9. Barretto ACP, Cardoso MN, Cardoso JN (2010) Iron deficiency in heart failure patients. Rev Bras Hematol Hemoter 32: 89-94.

10. Latado AL (2009) Diet Prescription in Chronic Heart Failure: Why Don’t We Do It?.Arq Bras Cardiol 93: 454-5.

11. Okoshi MP, Romeiro FG, Paiva SAR, Okoshi K (2013) Heart Failure-Induced Cachexia. Arq Bras Cardiol 100: 476-82.

12. Boagev RC (2010) Cost considerations in the treatment of heart failure. Texas Heart Ins J 37: 557-8.

13. Sahade V, Passos LCS (2005) Prevalence of malnutrition in heart failure patients. Rev Bras Nutr Clin 20: 65-70.

14. Hernandéz MA, Patinõ AF (2012) Consideraciones nutricionales en el paciente com falla cardíaca crônica. Rev ColombCardiol 19: 312-9.

15. Witte KA, Clark AL (2001) Chronic heart failure and micronutrients. J Am CollCardiol 37: 165-74.

16. Mustafa I, Leverve X (2001) Metabolic and nutritional disorders in cardiac cachexia. Nutrition 17: 756-60.

17. Sandek A, Bauditz J, Swidsinski A, Buhner S, Weber-Eibel J, et al. (2007) Altered intestinal function in patients with chronic heart failure. J Am CollCardiol 50: $1561-9$.

18. Witte K, Clark A (2002) Nutritional abnormalities contributing to cachexia in chronic illness. Int J cardiol 85: 23-31.

19. Obisesan TO, Toth MJ, Donaldson K, Gottlieb SS, Fisher ML, et al. (1996) Energy expenditure and symptom severity in men with heart failure. Am J Cardiol 77: $1250-2$.

20. Poehlman ET, Scheffers J, Gottlieb SS, Fischer ML, Vaitekevicius P (1994) Increased resting metabolic rate in patients with congestive heart failure. Ann Arch Intern Med 121: 60-2.

21. vonHaehling S, Doehner W, Anker SD (2007) Nutrition, metabolism, and the complex pathophysiology of cachexia in chronic heart failure. Cardiovasc Res 73: 298-309.

22. Aquilani R, Opasich C, Verri M, Boschi F, Febo O, et al. (2003) Is nutritional intake adequate in chronic heart failure patients? J Am CollCardiol 42: 1218-23. 23. Anker SD, Chua TP, Ponikowski P, Harrington D, Swan JW, et al. (1997) Hormonal changes and catabolic/anabolic imbalance in chronic heart failure and their importance for cardiac cachexia. Circulation 96: 526-34.

24. Anker SD, Ponikowski P, Varney S, Chua TP, Clark AL, et al. (1997) Wasting as independent risk factor for mortality in chronic heart failure. Lancet 349: 1050-3.

25. Gomez MJP, Gomez PC (2008) Evaluation of the nutritional status em com heart failure patients (II). Enferm Cardiol 2008: 46-50.

26. Palomas JLB et al. (2011) Ladesnutricio’nenlamortalidad Influence of long-term patients hospitalized for heart failure. Rev Esp Cardiol 64: 725-8.

27. Anker SD, Coats AJ (1999) Cardiac cachexia: a syndrome with impaired survival and immune and neuroendocrine activation. Chest 115: 836-47.

28. Mijan A, Martin E, Mateo B (2006) cardiac cachexia. Nutr Hosp 21: 84-93.

29. Vieira LP, Caçapava CR, Nakasato M (2004) Cardiac cachexia: a challenge to the dietician. Rev Bras Nutr Clin 19: 138-42.

30. Evans WJ, Morley JE, Argiles J, Bales C, Baracos V, et al. (2008) Cachexia: a new definition. ClinNutr. 27: 793-9.

31. vonHaehling S, Stepney R, Anker SD (2010) Advances in understanding and treating cardiac cachexia: highlights from the 5th Cachexia Conference. Int J Cardiol 144: 347-9.

32. Brink M, Anwar A, Delafontaine P (2002) Neurohormonal factors in the development of catabolic/anabolic imbalance and cachexia. Int J Cardiol 85: 111-21.

33. Genth-Zotz S, Bolger AP, Kalra PR, Coats AJ, Volk HD et al. (2004) Heatshockprotein 70 in patientswithchronicheartfailure: relation to disease severity and survival. Int J Cardiol 96: 397-401

34. von Haehling S, Genth-Zotz S, Anker SD, Volk HD (2002) Cachexia: a therapeutic approach beyondcitokine antagonismo. Int J Cardiol 85: 173-83.

35. Anker SD, von Haehling S (2004) Inflammatorymediators in chronicheartfailure: an overview. Heart 90: 464-70.

36. Baumann H, Gauldie J (1994) The acutephase response. Immunol Today 15: 74-80.

37. Kotler DP (2000) Cachexia. Ann Intern Med 133: 622-34.

38. Gut AL, Sugizaki MM, Okoshi MP, Carvalho RF, Pai-Silva MD, et al. (2008) Food restriction impairs myocardial inotropic response to calcium and betaadrenergic stimulation in spontaneously hypertensive rats. Nutr Res 28: 722-7.

39. Okoshi MP, Okoshi K, Matsubara LS, Dal Pai-Silva M, Gut AL, et al. (2006) Myocardial remodeling and dysfunction are induced by chronic food restriction in spontaneously hypertensive rats. Nutr Res 26: 567-72.

40. King D, Smith ML, Chapman TJ, Stockdale HR, Lye M (1996) Fat malabsorption in elderly patients with cardiac cachexia. Age Ageing 25: 144-9. 
41. Araújo JP, Lourenço P, Rocha-Gonçalves F, Ferreira A, Bettencourt P (2011) Nutritional markers and prognosis in cardiac cachexia. Int J Cardiol 146: 359-63.

42. Anker SD, Negassa A, Coats AJ, Afzal R, Poole-Wilson PA, et al. (2003) Prognostic importance of weight loss in chronic heart failure and the effect of treatment with angiotensin-converting-enzyme inhibitors: an observational study. Lancet 361: 1077-83.

43. Kenchaiah S, Evans JC, Levy D, Wilson PWF, Benjamin EJ, et al. (2002) Obesity and the risk of heart failure. N Engl J Med 347: $305-13$.

44. Thrainsdottir IS, Aspelund T, Gudnason V, Malmberg K, Sigurdsson G, et al. (2007) Increasing glucose levels and BMI predict future heart failure: experience from the Reykjavík Study. Eur J Heart Fail 9: 1051-7.

45. Cano M et al. (2010) Assessment body in patients with renal insufficiency lacomposición crônica .Nutr Hosp 25: 682-7.

46. Rocha IE, Victor EG, Braga MC, Barbosa e Silva O, Becker Mde M (2007) Echocardiography Evaluation for Asymptomatic Patients with Severe Obesity. Arq Bras Cardiol 88: 52-8.

47. Sharma S, Adrogue JV, Golfman L, Uray I, Lemm J, et al. (2004) Intramyocardial lipid accumulation in the failing human heart resembles the lipotoxic rat heart. FASEB J 18: 1692-700

48. Poornima IG, Parikh P, Shannon RP (2006) Diabetic cardiomyopathy:the search for a unifying hypothesis. Circ Res 98: 596-605.

49. Ingelsson E, Sundström J, Ärnlöv J, Zethelius B, Lind L (2005) Insulin Resistance and Risk of Congestive Heart Failure. JAMA $294:$ 334-41.

50. Gustafsson F, Kragelund CB, Torp-Pedersen C, Seibaek M, Burchardt H, et al. (2005) Effect of obesity and being overweight on long-term mortality in congestive heart failure: influence of left ventricular systolic function. Eur Heart J 26: 58-64.

51. Kalnatar-Zadeh K, Block G, Horwich TB, Fonarrow GC (2004) Reverse epidemiology of conventional cardiovascular risk factors in patients with heart failure. J Am Coll Cardiol 43: 1439-44.

52. Horwich TB, Fonarrow GC, Hamilton MA, MacLellan WR, Woo MA, et al. (2001) The relationship between obesity and mortality in patients with heart failure. J Am Coll Cardiol 38: 789-95.

53. Davos CH, Doehner W, Rauchhaus M, Cicoira M, Francis DP, et al. (2003) Body mass and survival in patients with the chronic heart failure without cachexia: the importance of obesity. J Card Fail 9:29-35.

54. Lainscak M, Von Haehling S, Doehner W, Anker SD (2012) The obesity paradox in chronic disease: facts and numbers. J Cachexia Sarcopenia Muscle 3: 1-4. 55. Artham SM, Ventura HO (2007) Insuficienciacardiaca and the "paradox of obesidade: lahistoriacontinúa. RevEspCardiol 60: $1113-7$.

56. Banack HR, Kaufman JS (2013) The obesity paradox explained. Epidemiology 24: 461-2.

57. Dorner TE, Rieder A (2010) Obesity paradox or reverse epidemiology: is high body weight a protective factor for various chronic conditions. Dtsch Med Wochenschr 135: 413-8.

58. Lenz M, Richter T, Mühlhauser I (2009) The morbidity and mortality associated with overweight and obesity in adulthood: a systematic review. Dtsch Arzteblint 106: 641-8.

59. Dyer A, Stamler J, Garside DB et al. (2004) Long-term consequences of body mass index for cardiovascular mortality: the Chicago Heart Association Detection Project in Industry study. Ann Epidemiol 14: 101-8.

60. Oreopoulos A, Padwal R, Kalantar-Zadeh K et al. (2008) Body mass index and mortality in heart failure: a meta-analysis. Am Heart J 156: 13-22.

61. Pinheiro AS et al. (2007) Obesity: protective factor in patients with heart failure? Rev Bras Nutr 22: 20-7.

62. BarretoACP (2003) Obesity and heart failure. Rev Assoc Med Bras 49: 2-3.

63. Campillo B, Paillaud E, Uzan I, Merlier I, Abdellaoui M, et al. (2004) Value of body mass index in the detection of severe malnutrition: influence of the pathology and changes in anthropometric parameters. Clin Nutr 23: 551-9.

64. Zuchinali P, Souza Gc, Alves Fd, Goldraich LA et al. (2013) Triceps Skinfold as a Prognostic Predictor in Outpatient Heart Failure. Arq Bras Cardiol 101: 434-41.

65. Yamauti AK, Ochiaia ME, Bifulo PS de Arajio MA, Alanoso RR et al. (2006) Subjective Global Assessment of Nutritional Status in Cardiac Patients. Arq Bras Cardiol 87: 772-7.

66. Britto EP, Mesquita ET (2008) Bioelectrical Impedance Analysis in Heart Failure Rev Soc Cardiol RJ 21: 178-83.

67. Llames L, Baldomero V, Lelgsas ML, Rodota Me (2013) Phase values from the angle by bioelectrical impedance ; nutritional status and prognostic value. Nutric Hosp 28: 286-95.

68. Barbosa-Silva MC, Barrows AJ, Heymsfield SB, Pierson RN (2005) Bioelectrical impedance analysis: population reference values for phase angle by age and sex. American Journal Clinical Nutrition 82: 49-52.

69. Silva RD, Dutra MPV, Ignêz M, Elsas G, Azevedo ZMA et al. (2007) Associação between phase angle and I Gravidade PRISM gives Sepse . RevBras Ter Int 19: 297-303.

70. Omran ML, Morley JE (2000) Assessment of protein energy malnutrition in older persons, part I: History, examination, body composition, and screening tools. Nutrition 16: 50-63.

71. Omran ML, Morley JE (2000) Assessment of protein energy malnutrition in older persons. Part II: Laboratory evaluation. Nutrition 16: 131-40.

72. Bocchi EA, Marcondes-Braga FG, Ayub-Ferreira SM, Rohde LE, Oliveira WA, et al. (2009) Brazilian Society of Cardiology. III Brazilian Guidelines on Chronic Heart Failure. Arq Bras Cardiol 93: 1-71.

73. Clyde W. Yancy, Mariell Jessup, BiykemBozkurt, Javed Butler, Donald E. Casey, et al. (2013) Guideline for the Management of Heart Failure: A Report of the American College of Cardiology Foundation/American Heart Association ACCF/AHA . Circulation 128: 240-327.

74. Ghali JK (2009) Anemia and heart failure. Curr Opin Cardiol 24: 172-8.

75. Frediani JK, Reilly CM, Higgins M, Clark PC, Gary RA, et al. (2013) Quality and Adequacy of Dietary Intake in a Southern Urban Heart Failure Population. Cardiovasc Nurs 28: 119-28.

76. Lourenço BH, Vieira LP, Macedo A, Nakasato M, Marucci Mde F, et al. (2009) Nutritional Status and Adequacy of Energy and Nutrient Intakes among Heart Failure Patients. Arq Bras Cardiol 93: 541-8 
77. Rujinski MN (2007) Nutrición em La insuficiencia cardíaca um granes labón. Ver Insuf Card 2: 115-7.

78. Akner G, Cederholm T (2001) Treatment of protein-energy malnutrition in chronic nonmalignant disorders. Am J Clin Nutr 74: 6-24.

79. Nodari S, Triggiani M, Campia U, Manerba A, Milesi G, et al. (2011) Effects of n-3 polyunsaturated fatty acids on left ventricular function and functional capacity in patients with dilated cardiomyopathy. J Am Coll Cardiol 57: 870-9.

80. Heart Failure Society of America (2006) Executive summary: HFSA 2006 comprehensive heart failure practice guideline. J Card Fail 12:10-38.

81. Heymsfield SB, Smith J, Redd S, Whitworth HB (1981) Nutrition support in cardiac failure. Surg Clin North Am 61: 635-52.

82. Quinn T, Askanazi J (1987) Nutrition and cardiac disease. Crit Care Clin 3: 167-84.

83. Sandek A, Doehner W, Anker SD, von Haehling S (2009) Nutrition in heart failure: an update. Curr Opin Clin Nutr Metab Care 12: 384-91.

84. Zhao YT, Shao L, Teng LL, Hu B, Luo Y, et al. (2009) Effects of n-3 polyunsaturated fatty acid therapy on plasma inflammatory markers and N-terminal probrain natriuretic peptide in elderly patients with chronic heart failure. J Int Med Res 37: 1831-41.

85. Yamagishi K, Iso H, Date Ch, Fukui M, Wakai K, et al. (2008) Fish $\Omega$-3 polyunsaturated fatty acids, and mortality from cardiovascular diseases in a nationwide community-based cohort Japanese men and women. J Am Coll Cardiol 52: 988-96.

86. GISSI-HF Investigators (2008) Effect of n-3 polyunsaturated fatty acids in patients with chronic heart failure (the GISSI-HF trial): a randomized double-blind, placebo-controlled trial. Lancet 372: 1223-30.

87. de Lorgeril M, Salen P, Accominotti M, Cadau M, Steghens JP, et al. (2001) Dietary and blood antioxidants in patients with chronic heart failure. Insights into the potential importance of selenium in heart failure. Eur J Heart Fail 3: 661-9.

88. Cunha S, Albanesi Filho FM, Bastos VLFC, Antelo DS, Souza MM (2002) Thiamin, selenium, and copper levels in patients with idiopathic dilated cardiomyopathy taking diuretics. Arq Bras Cardiol 79: 4540-65.

89. Seligmann H, Halkin H, Rauchfleisch S, Kaufmann N, Motro M, et al. (1991) Thiamine deficiency in patients with congestive heart failure receiving longterm furosemide therapy: a pilot study. Am J Med 91: 151-5.

90. Witte KK, Nikitin NP, Parker AC, von Haehling S, Volk HD, et al. (2005) The effect of micronutrient supplementation on quality-of-life and left ventricular function in elderly patients with chronic heart failure. Eur heart J 26: 2238-44.

91. Heart Failure Society of America1, Lindenfeld J, Albert NM, Boehmer JP, Collins SP, et al. (2010) HFSA 2010 comprehensive heart failure practice guideline. J Card Fail 16: 1-194.

92. Dickstein K, Cohen-Solal A, Filippatos G, McMurray JJ, Ponikowski P, et al. (2008) ESC guidelines for the diagnosis and treatment of acute and chronic heart failure 2008: the Task Force for the Diagnosis and Treatment of Acute and Chronic Heart Failure 2008 of the European Society of Cardiology: developed in collaboration with the Heart Failure Association of the ESC (HFA) and endorsed by the European Society of Intensive Care Medicine (ESICM). Eur Heart J 29: 2388-442.

93. Lennie TA, Song EK, Wu JR, Chung ML, Dunbar SB, et al. (2001) Three gram sodium intake is associated with longer event-free survival only in patients with advanced heart failure. J Card Fail 17: 325-30.

94. Payne-Emerson H, Lennie TA (2008) Nutritional considerations in heart failure. Nurs Clin North Am 43: 117-32.

95. Rocha RM, Silva GV, de Albuquerque DC, Tura BR, Albanesi Filho FM (2008) Influence of Spironolactone Therapy on Thiamine Blood Levels in Patients with Heart Failure. Arq Bras Cardiol 90: 324-8.

96. Reyes A, Leary W (1993) Renal excretory responses to single and repeated administration of diuretics in healthy subjects: clinical connotations. Cardiovasc Drugs Ther 7: 29-44.

97. Lip GY, Gibbs CR, Beevers DG (2000) ABC of heart failure: aetiology. BMJ 320: 104-7.

98. Yui Y, Itokawa Y, Kawai C (1980) Furosemide induced thiamine deficiency. Cardiovasc Res 14: 537-40.

99. Sole MJ, Jeejeebhoy KN (2002) Conditioned nutritional requirements: therapeutic relevance to heart failure. Herz 2: 174-8.

100. Pilz S, Tomaschitz A, Marz W, Drechsler C, Ritz E, et al. (2011) Vitamin D, cardiovascular disease and mortality. Clin Endocrinol 75: 575-84.

101. Brewer LC, Michos E.D, Reis JP (2011) Vitamin D in atherosclerosis, vascular disease, and endothelial function. Curr Drug Targets 12: 54-60.

102. Soskić S, Stokić E, Isenović ER (2014) The relationship between vitamin D and obesity. Curr Med Res Opin 30: 1197-9.

103. Multani SK, Sarathi V, Shivane V, Bandgar TR, Menon PS, et al. (2010) Study of bone mineral density in resident doctors working at a teaching hospital. J. Postgrad. Med 56: 65-70.

104. Marwaha RK, Puri S, Tandon N, Dhir S, Agarwal N, et al. (2011) Effects of sports training \& nutrition on bone mineral density in young Indian healthy females. Indian J Med Res 134: 307-13.

105. Baidya A, Chowdhury S, Mukhopadhyay S, Ghosh S (2012) Profile of vitamin D in a cohort of physicians and diabetologists in Kolkata. Indian J Endocrinol Metab 16: 416-7.

106. Ritu G, Ajay G (2014) Vitamin D deficiency in India: Prevalence, causalities and interventions. Nutrients 6: 725-75.

107. Mora C, Myers RA, Coll M, Libralato S, Pitcher TJ, et al. (2009) Management effectiveness of the world's marine fisheries. PLoS Biol 7: 1-11.

108. Ku YC, Lin ME, Ku Cs, Liu TY, Lin SL (2013) Relationship between vitamin D deficiency and cardiovascular disease. World J Cardiol. 5: $337-46$.

109. Ellam T, Hameed A, ulHaque R, Muthana M, Wilkie M (2014) Viatamin D deficiency and exogenous vitamin D excess similarly increase diffuse atherosclerosis calcification in apolipoprotein E knockout mice. PLos One 9: 887-67.

110. Groenveld HF, Januzzi JL, Damman K, van Wijngaarden J, Hillege HL, et al. (2008) Anemia and mortality in heart failure patients a systematic review and meta-analysis. J Am CollCardiol 52: 818-27.

111. Murphy CL, McMurray JJ (2003) Approaches to the treatment of anaemia in patients with chronic heart failure. Heart Fail Rev 13: 431-8. 
112. Silverberg DS, Wexler D, Blum M, Wollman Y, Iaina A (2003) The cardio-renal syndrome: does it exist? Nephrol Dial Transplant 18: 7-12.

113. Gil P, Justo S, Caramelo C (2005) Cardio-renal failure: an emerging clinical entity. Nephrol Dial Transplant 20: 1780-3.

114. Villacorta H, Saenz-Tello BF, Santos EB, Steffen R, Wiefels C, et al. (2010) Renal Dysfunction and Anemia in Patients with Heart Failure with Reduced versus Normal Ejection Fraction. Arq Bras Cardiol 94: 378-84.

115. Reis FJFB, Fernandes AMS, Bitencourt AGV, Neves FBCS, Kuwano AY, et al. (2009) Prevalence of Anemia and Renal Insufficiency in Non-Hospitalized Patients with Heart Failure. Arq Bras Cardiol 93: 268-74.

116. Marecos C, Falcão LM (2010) Anemia and cardiorenal syndrome in heart failure: review article. Rev Port Med Intern 17: $263-73$.

117. Pereira CA, Roscani MG, Zanati SG, Matsubara BB (2013) Anemia, Heart Failure and Evidence-Based Clinical Management. Arq Bras Cardiol 101: 87-92.

118. Keith ME, Jeejeebjoy KN, Langer A, Kurian R, Barr A, et al. (2001) A Controlled trial of vitamin E supplementation in patients with congestive heart failure. Am J Clin Nutr 73: 219-24.

119. Fuentes J, Salmon A, Silver M (2006) Acute and chronic oral magnesium supplementation: effects on endothelial function, exercise capacity, and quality of life in patients with symptomatic heart failure. Congest Heart Fail 12: 9-13.

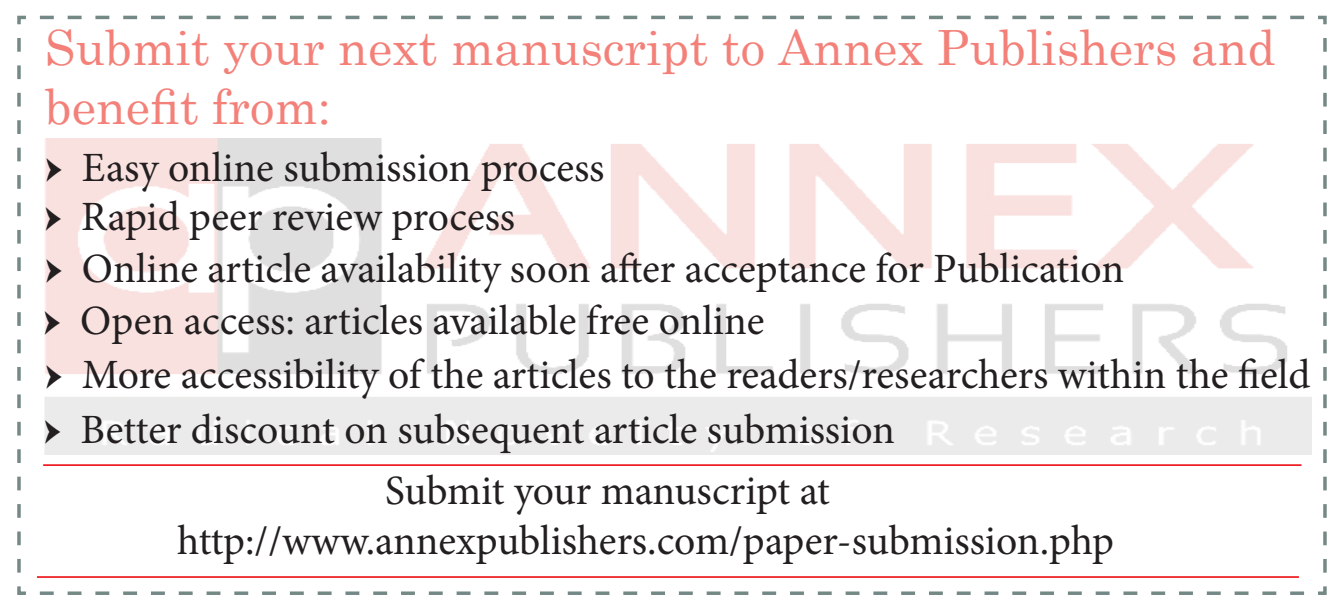

